\title{
The Multi-Isotope Process (MIP) Monitor Project: FY12 Progress and Accomplishments
}

$\begin{array}{ll}\text { JB Coble } & \text { SE Bender } \\ \text { CR Orton } & \text { KJ Dayman } \\ \text { DV Jordan } & \text { K Unlu } \\ \text { JM Schwantes } & \text { S Landsberger }\end{array}$

September 2012

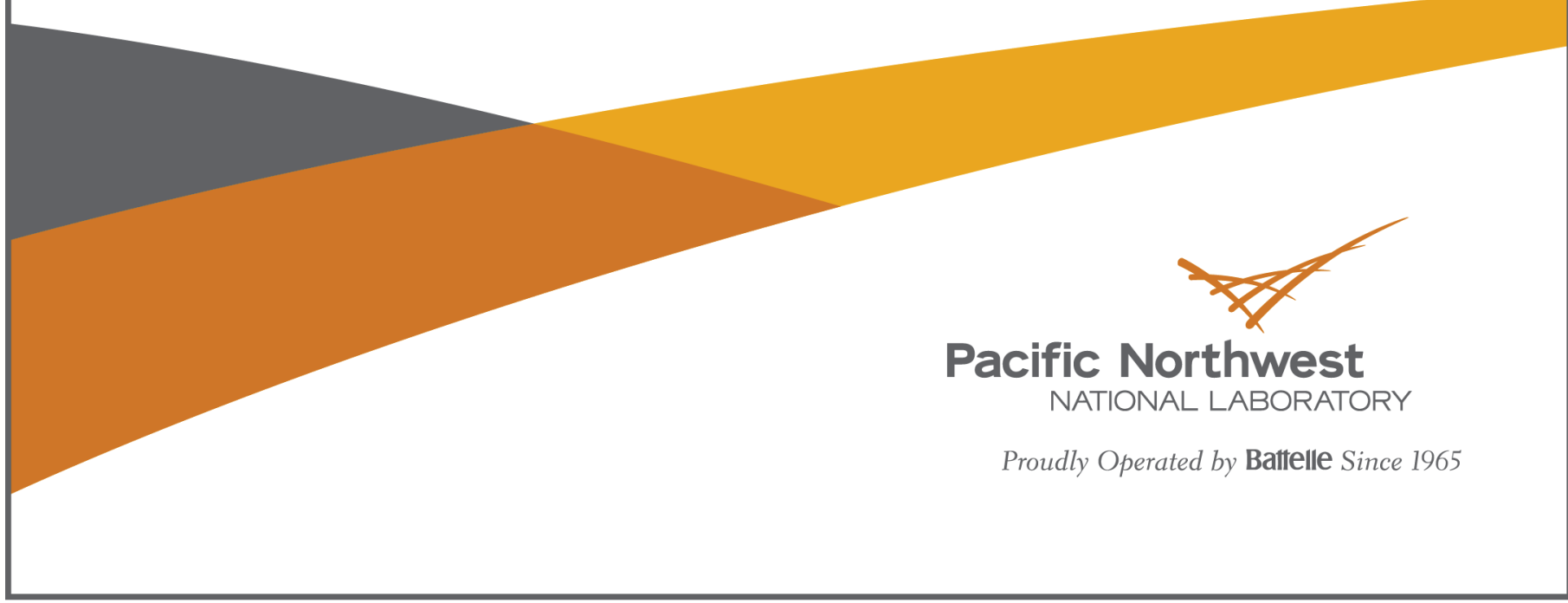




\title{
DISCLAIMER
}

This report was prepared as an account of work sponsored by an agency of the United States Government. Neither the United States Government nor any agency thereof, nor Battelle Memorial Institute, nor any of their employees, makes any warranty, express or implied, or assumes any legal liability or responsibility for the accuracy, completeness, or usefulness of any information, apparatus, product, or process disclosed, or represents that its use would not infringe privately owned rights. Reference herein to any specific commercial product, process, or service by trade name, trademark, manufacturer, or otherwise does not necessarily constitute or imply its endorsement, recommendation, or favoring by the United States Government or any agency thereof, or Battelle Memorial Institute. The views and opinions of authors expressed herein do not necessarily state or reflect those of the United States Government or any agency thereof.

\author{
PACIFIC NORTHWEST NATIONAL LABORATORY \\ operated by \\ BATTELLE \\ for the \\ UNITED STATES DEPARTMENT OF ENERGY \\ under Contract DE-AC05-76RL01830
}

Printed in the United States of America
Available to DOE and DOE contractors from the Office of Scientific and Technical Information,
P.O. Box 62, Oak Ridge, TN 37831-0062;
ph: (865) 576-8401
fax: $(865)$ 576-5728
email: reports@adonis.osti.gov

\begin{abstract}
Available to the public from the National Technical Information Service, U.S. Department of Commerce, 5285 Port Royal Rd., Springfield, VA 22161 ph: (800) 553-6847 fax: $(703) 605-6900$ email: orders@ntis.fedworld.gov online ordering: http://www.ntis.gov/ordering.htm
\end{abstract}

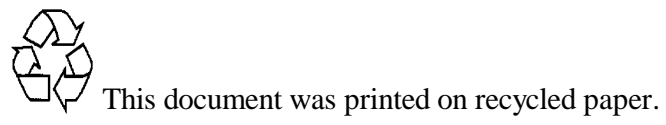




\section{The Multi-Isotope Process (MIP) Monitor Project: FY12 Progress and Accomplishments}

\author{
JB Coble \\ CR Orton \\ DV Jordan \\ JM Schwantes
}

\author{
SE Bender ${ }^{(a)}$ \\ KJ Dayman ${ }^{(b)}$ \\ $\mathrm{K} \mathrm{Unlu}^{\text {(a) }}$ \\ S Landsberger ${ }^{(b)}$
}

September 2012

Prepared for the U.S. Department of Energy under Contract DE-AC05-76RL01830

Pacific Northwest National Laboratory Richland, Washington 99352

(a) Pennsylvania State University, University Park, Pennsylvania 16802

(b) University of Texas at Austin, Austin, Texas 78712 



\section{Summary}

The Multi-Isotope Process (MIP) Monitor, being developed at Pacific Northwest National Laboratory (PNNL), provides an efficient approach to monitoring the process conditions in reprocessing facilities in support of the goal of "... (minimization of) the risks of nuclear proliferation and terrorism." The MIP Monitor measures distributions of a suite of indicator (radioactive) isotopes present within product and waste streams of a nuclear reprocessing facility. These indicator isotopes are monitored on-line by gamma spectrometry and compared, in near-real-time, to spectral patterns representing "normal" process conditions using multivariate pattern recognition software. The monitor utilizes this multivariate analysis and gamma spectroscopy of reprocessing streams to detect small changes in the gamma spectrum, which may indicate changes in process conditions. Multivariate analysis methods common in chemometrics, such as principal component analysis (PCA) and partial least squares regression (PLS), act as pattern recognition techniques, which can detect small deviations from the expected, nominal condition. By targeting multiple gamma-emitting indicator isotopes, the MIP Monitor approach is compatible with the use of small, portable, relatively high-resolution gamma detectors that may be easily deployed throughout an existing facility. The automated multivariate analysis can provide a level of data obscurity, giving a built-in information barrier to protect sensitive or proprietary operational data. Proof-of-concept simulations and experiments have been performed in previous years to demonstrate the validity of this tool in a laboratory setting. Development of the MIP Monitor approach continues to evaluate the efficacy of the monitor for automated, real-time or near-real-time application. This report details follow-on research and development efforts sponsored by the U.S. Department of Energy Fuel Cycle Research and Development related to the MIP Monitor for fiscal year 2012 (FY12). Specific aspects of research completed in FY12 include:

- An automated algorithm for characterizing dissolved spent fuel samples according to reactor type, initial enrichment, burn-up, and cooling time was developed and documented. Milestone report submitted in July 2012.

- A framework for characterizing the propagation of uncertainty in multivariate analysis of gamma spectra was developed. Experimental work to provide data to further develop and confirm the approach was performed; analysis of this data is planned for FY13.

- Spent fuel solutions were maintained to provide continued access to spent fuel solutions for testing of the MIP Monitor. Samples are being transferred to Pennsylvania State University (PSU) to support their work related to the MIP Monitor.

- Data from the bench-scale flow loop designed and constructed in FY11 were analyzed. Results led to modifications of the flow loop to provide better process control and utilize event mode counting. Data collected on the modified loop will be analyzed in early FY13.

- One graduate student, Kenny Dayman at University of Texas at Austin (UT-Austin), published a master's thesis on work directly related to the MIP Monitor project.

- Efforts continue on several fronts to engage international partners with the intent to collaborate in order to gain access to large amounts of reprocessing data for further MIP Monitor development.

- A proposal was developed and submitted to DOE-NE and NA-24 to instrument the H-Canyon reprocessing facility at Savannah River National Laboratory (SRNL) with gamma detectors in order to collect data to further develop and demonstrate the MIP Monitor. 
- The MIP Monitor research and development was presented and published in several forums, including several related to the MIP Monitor that were funded either internal to the lab or whose funding was shared between U.S. Department of Energy (DOE) programs. Lists of key publications and presentations follow.

\section{Publications}

Orton CR, CG Fraga, RN Christensen and JM Schwantes. 2012. "Proof of Concept Experiments of the Multi-Isotope Process Monitor: An Online, Nondestructive, Near Real-Time Monitor for Spent Nuclear Fuel Reprocessing Facilities." Nuclear Instruments and Methods in Physics Research Section A: Accelerators, Spectrometers, Detectors and Associated Equipment 672:38-45.

Orton CR, CG Fraga, KJ Dayman, SE Bender, S Landsberger, K Unlu, and JM Schwantes. 2012. "The Multi-Isotope Process (MIP) Monitor: a Near-Real-Time, Non-Destructive Monitor for Reprocessing," Proceedings of GLOBAL 2011. Paper No. 384545, Makuhari, Japan, December 11-16, 2011.

Bender SE, K Ünlü, CR Orton, and JM Schwantes. 2012. “Geant4 Model Validation of Compton Suppressed System for Process Monitoring of Spent Fuel." Journal of Radioanalytical and Nuclear Chemistry. DOI: 10.1007/s10967-012-1988-3.

Bryan SA, TG Levitskaia, JM Schwantes, CR Orton, JM Peterson, and AJ Casella. 2012. "Monitoring, Controlling and Safeguarding Radiochemical Streams at Spent Fuel Reprocessing Facilities, Part 1: Optical Spectroscopic Methods." International Journal on Nuclear Energy Management and Safety. DOI: 10.5848/IJNEMS.2012.00002.

Schwantes JM, SA Bryan, CR Orton, TG Levitskaia, and CG Fraga. 2012. "Monitoring, Controlling and Safeguarding Radiochemical Streams at Spent Fuel Reprocessing Facilities, Part 2: Gamma-Ray Spectroscopic Methods." International Journal on Nuclear Energy Management and Safety. DOI: 10.5848/IJNEMS.2012.00003.

Schwantes JM, SA Bryan, CR Orton, TG Levitskaia, SH Pratt, CG Fraga, and JB Coble. "Advanced Process Monitoring Safeguards Technologies at Pacific Northwest National Laboratory." Procedia Chemistry (in press).

\section{Presentations}

Presenters indicated in bold.

Schwantes JM, SA Bryan, CR Orton, TG Levitskaia, and CG Fraga. 2011. "Monitoring, Controlling and Safeguarding Radiochemical Streams at Spent Fuel Reprocessing Facilities with Optical and Gamma-Ray Spectroscopic Methods.” Presented by Jon Schwantes (Invited Speaker) at INMM/ESARDA 7th Workshop, Marseille, France on October 17, 2011.

Orton CR, CG Fraga, JW Hayes, SE Bender, K Unlu, KJ Dayman, S Landsberger, R Christensen, and JM Schwantes. 2011. "The Multi-Isotope Process Monitor: FY11 Accomplishments." Presented at 2011 Fuel Cycle R\&D, Chicago, Illinois, on November 9, 2011. 
Bender S*, K Unlu, and C Orton. "Monte Carlo Modeling of Compton Suppression for Spent Fuel Material Accountancy.” In 2011 ANS Winter Meeting, Washington D.C., November 2011.

Sharpe SW, CR Orton, WK Pitts, L Chilton, and JG Fankhauser. 2011. "Pacific Northwest National Laboratory is Your Non-proliferation R\&D Partner." Presented at University Industry Technical Interchange on December 6, 2011.

Orton CR, CG Fraga, KJ Dayman, SE Bender, S Landsberger, K Unlu, and JM Schwantes. 2011. "The Multi-Isotope Process (MIP) Monitor: a Near-Real-Time, Non-Destructive Monitor for Reprocessing." Presented by David Wootan at Global 2011, Makuhari Messe, China on December 14, 2011.

Dayman K* and S. Landsberger. 2012. "Characterization of Spent Nuclear Fuel Using Multivariate Signatures.” In American Nuclear Society Student Conference, Las Vegas, Nevada, April 2012.

DaymanK *. "Multivariate Analysis Applied to the Characterization of Spent Nuclear Fuel." 2012. Presented at Nuclear Forensics Graduate Fellowship (NFGF) Academic Laboratory Collaboration Meeting, Oak Ridge, Tennessee, June 2012.

Schwantes JM, SA Bryan, DC Duckworth, TG Levitskaia, SH Pratt, JB Coble, M Liezers, GL Hart, and CR Orton. 2012. "Advanced Process Monitoring Safeguards Technologies at Pacific Northwest National Laboratory." Presented at ATALANTE 2012 International Conference, Montpellier, France on August 30, 2012.

Bender S*, K Unlu, CR Orton, and JM Schwantes. 2012. "Monte Carlo Modeling of Compton Suppression for Spent Fuel Material Accountancy." Presented at MARC IX, Kona, Hawaii on March 28, 2012.

Dayman K*, C Orton, J Coble, and J Schwantes. 2012. "Characterization of Spent Nuclear Fuel Using Multivariate Analysis.” In 2012 ANS Winter Meeting, San Diego, California, November 2012.

Dayman K*, C. Orton, and S. Landsberger. 2012. "Applications of Statistical Learning Techniques to Gamma Spectra: Process Monitoring and the Characterization of Spent Nuclear Fuel." In Southwest Regional Meeting of the American Chemistry Society, Austin, Texas, November 2012.

\footnotetext{
${ }^{*}$ Presented by graduate student.
} 



\section{Acronyms and Abbreviations}

$\begin{array}{ll}\text { BWR } & \text { boiling water reactor } \\ \text { DOE } & \text { U.S. Department of Energy } \\ \text { HPGe } & \text { high-purity germanium } \\ \text { iPLS } & \text { interval-PLS } \\ \text { LWPLS } & \text { locally weighted PLS } \\ \text { MC\&A } & \text { material control and accounting } \\ \text { MIP } & \text { Multi-Isotope Process } \\ \text { NA-24 } & \text { Office of Nonproliferation and International Security } \\ \text { OTA } & \text { Office of Technology Assessment } \\ \text { PCA } & \text { principal component analysis } \\ \text { PCR } & \text { principal component regression } \\ \text { PLS } & \text { partial least squares regression } \\ \text { PLSDA } & \text { PLS-discriminate analysis } \\ \text { PNNL } & \text { Pacific Northwest National Laboratory } \\ \text { PSU } & \text { Pennsylvania State University } \\ \text { PWR } & \text { pressurized water reactor } \\ \text { RMS } & \text { root mean square } \\ \text { RMSPE } & \text { root mean square percent error } \\ \text { SRNL } & \text { Savannah River National Laboratory } \\ \text { UT-Austin } & \text { University of Texas at Austin } \\ & \end{array}$





\section{Contents}

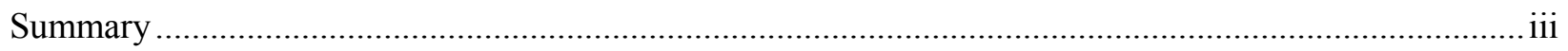

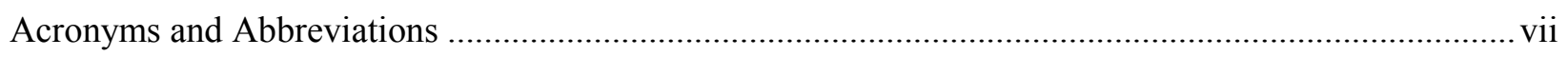

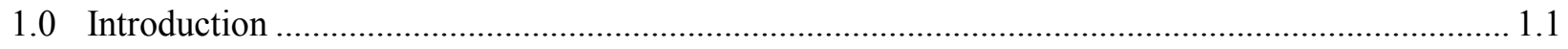

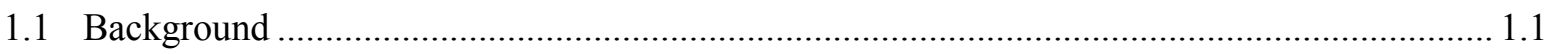

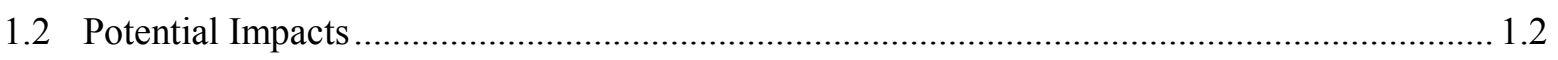

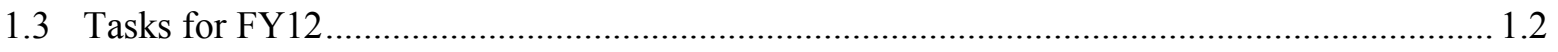

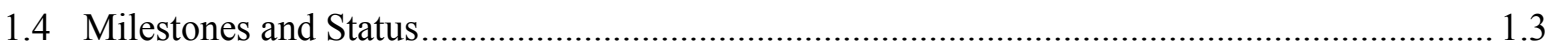

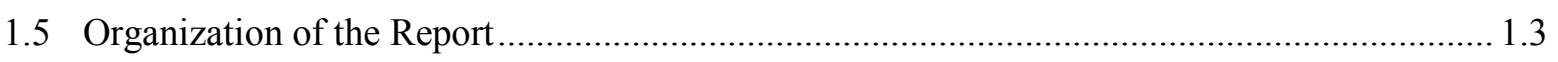

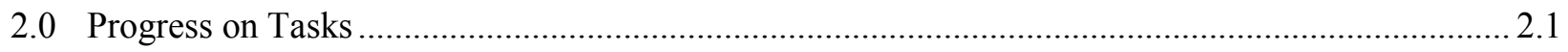

2.1 Task 1: Experimental Efforts to Advance the MIP Monitor Approach ................................ 2.1

2.2 Task 2: Enhanced Multivariate Techniques and Approaches ................................................ 2.1

2.3 Task 3: Enhanced Gamma-Ray Spectra Collection Techniques ........................................... 2.6

2.4 Task 4: Training of the Next Generation of Nuclear Scientists ............................................. 2.6

2.5 Task 5: Coordinating the MIP Monitor Project with Related Activities in Other

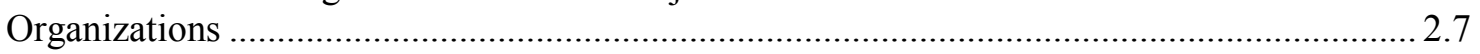

2.6 Task 6: Bench-Scale Flow Loop Experimentation and Analysis........................................ 2.7

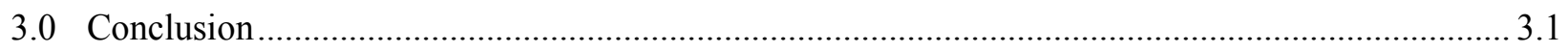

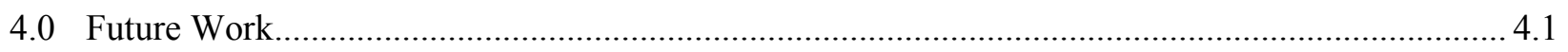

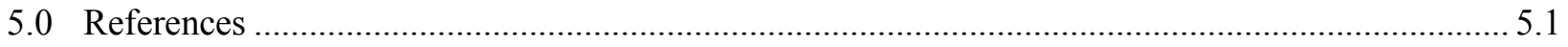




\section{Figures}

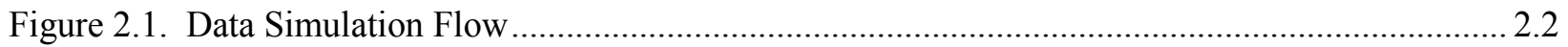

Figure 2.2. Flow Diagram for Automated Fuel Characterization Algorithm (Algorithm B)................. 2.4

Figure 2.3. Effect of Total Counts on Reconstruction Precision ......................................................... 2.6

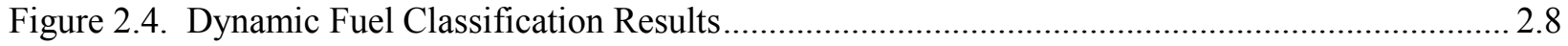

Figure 2.5. Photograph of the Updated Bench-Scale Flow Loop System.............................................. 2.9

\section{Tables}

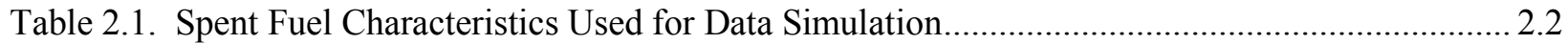

Table 2.2. HPGe Detector and Electronics Parameters for SYNTH Gamma Spectra Simulations .......... 2.3

Table 2.3. Fuel Characterization RMSPE for Parallel Prediction, Algorithm A, and Algorithm B ........ 2.4 


\subsection{Introduction}

In April 2010, the U.S. Department of Energy (DOE) issued a report to congress entitled, Nuclear Energy Research and Development Roadmap (DOE 2010). One of the four objectives listed for the DOE's nuclear energy research and development activities is Objective 4: "Understand and minimize the risks of nuclear proliferation and terrorism." The primary focus of this project is to aid in the achievement of this objective.

Conventional nuclear material control and accounting (MC\&A) at bulk handling facilities rely, in large part, on destructive analyses to quantify nuclear material and verify the location of all special nuclear material. Although their accuracy is superb, destructive analyses are extremely resourceintensive, have limited sampling rates, and are associated with a significant time lag from sampling to final reporting. In addition, the error associated with these analyses scales with the size of the facility (OTA 1995, Appendix A). As such, highly precise destructive measurements of special nuclear material alone at large facilities may not be adequate to ensure diversions have not occurred. While it is not likely that more precise destructive measurement techniques will be developed in the near future, intelligent integration of a variety of on-line process monitoring tools capable of near real-time, non-destructive measurements may be successful in adequately safeguarding even the largest envisioned facility. A combination of these techniques utilizing both material accountancy and augmented material control via continuous process flow sheet verification could provide a more robust framework for MC\&A.

Pacific Northwest National Laboratory (PNNL) is currently developing and demonstrating a technology capable of monitoring conditions at a nuclear reprocessing plant on-line, non-destructively, and in near real-time called the Multi-Isotope Process (MIP) Monitor (Smith et al. 2007; Orton et al. 2008; Schwantes et al. 2008; Orton et al. 2009a; Orton et al. 2009b; Schwantes et al. 2009). The MIP Monitor is designed to track changes in the distribution of gamma-emitting elements as evidence that process conditions are changing (Benedict et al. 1981). Online process surveillance by the MIP Monitor is accomplished by coupling the gamma spectra recorded from process streams with multivariate analysis. Multivariate analysis can evaluate the spectral pattern of the gamma emitting nuclides in near-real-time for statistically relevant signs of significant changes to the process. By watching the process for unexpected changes, the MIP Monitor can warn of possible process migration to an unintended or undeclared operation. Because the pattern comparison is automatic and autonomous, proprietary operational or fuel information can be protected while assuring process integrity. However, if desired, process conditions can also be quantified using alternate multivariate calibration techniques, making the monitor a potentially valuable part of a comprehensive process control system. In addition, because the monitor is trained on the gamma rays inherent to nuclear fuel, the MIP monitor technique is not limited to aqueous reprocessing but can be applied to other recycling systems. A more detailed overview of the MIP Monitor can be found in the following references (Smith et al. 2007; Orton et al. 2008; Schwantes et al. 2008; Orton et al. 2009a; Orton et al. 2009b; Schwantes et al. 2009).

\subsection{Background}

This research commenced in 2006 with initial scoping studies into the feasibility of the MIP Monitor concept through limited computer simulations. In fiscal year 2008 (FY08), the project was funded and proof-of-concept simulation studies were performed. The results successfully demonstrated the merit of the MIP Monitor approach. In late FY08 and into FY09, with help from the Office of Nonproliferation 
and International Security (NA-24), proof-of-concept experiments were initiated to confirm model results from the previous years. Since that time, experiments and simulations have been conducted to further characterize and enhance the performance of the MIP Monitoring approach. Experiments to date have focused on providing replicate data (which are required for multivariate analysis), as well as near-realtime data from well-characterized spent fuels. While great strides have been made in understanding how the MIP Monitor reacts to process changes and fuel characteristics, much remains to be done to further characterize the potential of the approach in actual deployments within continuous flow systems.

The overall goals of this project are to continue an assessment of the strengths and limitations of the MIP Monitoring approach for monitoring streams within a nuclear reprocessing facility and to seek opportunities to apply this technology at the pilot and industrial scale. As limitations and strengths are discovered, they will be addressed or capitalized upon in order to develop the MIP Monitor into an effective tool for safeguarding nuclear material and operator process control. The MIP Monitor will then aid in the accomplishment of Objective 4 of the Nuclear Energy Research and Development Roadmap to, “... minimize the risks of nuclear proliferation and terrorism" (DOE 2010).

\subsection{Potential Impacts}

Although the MIP Monitor is still in its infancy, the approach shows potential for providing cost saving improvements to domestic and international MC\&A as well as process monitoring. The MIP Monitor has the potential to increase process monitoring efficiency and effectiveness by providing continuous verification of process integrity, which should allow the number and frequency of costly destructive analysis measurements to be reduced at bulk handling facilities. In addition to MC\&A improvements, a mature MIP Monitor may also provide operators with a cost-effective process monitoring control tool. Current monitoring methods require highly radioactive grab samples to be collected from the process stream in order to confirm process conditions. The MIP Monitor could potentially monitor these process variables non-destructively and in near-real-time. Such an approach could significantly reduce operator costs as well as the doses received by analysts.

The MIP Monitor approach may also be an effective approach to spent fuel burn-up measurements, which are traditionally performed using conventional gamma spectroscopy. By focusing on multivariate patterns rather than the ratios of a few isotopes, changes in spectral patterns might be used to improve on the accuracy of conventional burn-up analysis. Increasing the accuracy of measured burn-up levels of spent fuel will increase the fidelity of the initial plutonium concentration value in spent fuel, providing a more accurate starting point for MC\&A.

\subsection{Tasks for FY12}

Tasks supporting the accomplishment of the overall goal of the MIP Monitor during FY12 include:

1. Continuing experimental efforts to more fully test and evaluate the MIP Monitoring approach, taking advantage of the stock of a variety of well-characterized spent nuclear fuel samples currently available at the hot cell facility at PNNL and using multiple detector types (such as HPGe, CZT, $\mathrm{LaBr} 3$, and $\mathrm{NaI}$ ) to collect spectra.

2. Enhancing multivariate techniques for recognizing and quantifying gamma ray spectral patterns and transitioning these efforts to near-real-time applications. This task includes continuing a detailed 
sensitivity analysis to identify specific gamma lines and signature nuclides influencing spectral changes as a function of process conditions.

3. Working with researchers at Pennsylvania State University (PSU) and University of Texas at Austin (UT-Austin) to investigate the feasibility of coincidence and anti-coincidence (Compton suppression) measurements as part of the MIP Monitoring approach to both enhance the signal-to-noise ratio and investigate the as-of-yet untapped gamma-gamma coincidence signals residing in spent fuel. This task relies heavily on the university to provide models and measurements. The measurements will be limited by what the universities can receive and handle; PSU continues to create a validated model of their Compton suppression system and apply it to other detector types.

4. Training of the next generation of nuclear scientists within the United States, including coordinating the graduate student efforts at the collaborating universities. This includes support for graduate students at UT-Austin and PSU.

5. Coordinating MPACT MIP Monitor scope with related activities in other programs (e.g., NE's separations campaign, NA-24 process monitoring campaign, and PNNL internal investments for developing new process monitoring technologies). This also involves coordinating with any potential domestic and international partners that might be able to provide operational data and/or facilities for additional MIP Monitor testing and research.

6. Using and modifying a simplified bench-scale flow loop to further develop and evaluate the MIP Monitor in a real-time environment.

\subsection{Milestones and Status}

Three milestones are associated with FY12:

i. Technical Memo describing Multivariate Analysis Progress

ii. Complete and Document Automatic Algorithm for MIP

iii. FY12 MIP Monitor Report

With the submission of this report (milestone 3), all of the milestones for FY12 have been completed.

\subsection{Organization of the Report}

This report summarizes the research in FY12 to further development of the MIP Monitor. Six tasks were defined for this effort; the following section describes the progress made on each of these tasks. Section 3 summarizes the major accomplishments in FY12. Finally, the work proposed to continue development of the MIP Monitor in FY13 and beyond is summarized in Section 4. 



\subsection{Progress on Tasks}

Six main tasks were defined to continue development of the MIP Monitor. The progress and accomplishments made during FY12 on each of these tasks is summarized in the following sections.

\subsection{Task 1: Experimental Efforts to Advance the MIP Monitor Approach}

Minimal experimental work was performed during FY12. Due to the extensive experimental activity during previous years, a large inventory of spent-fuel solutions is available at PNNL. A sample set of gamma standards mixed in various solutions were created and measured the samples using high-purity germanium (HPGe) detectors under previous work (funded through NA-241). Measurements of the samples by additional detectors types can help investigate the uncertainties associated with multivariate analysis of gamma spectra. In late FY12, measurements of these samples with a $\mathrm{LaBr}_{3}$ detector began. These measurements are expected to be completed in FY12, with data analysis and uncertainty characterization in early FY13.

\subsection{Task 2: Enhanced Multivariate Techniques and Approaches}

Development of an automated algorithm for characterizing dissolved used fuel samples was a major effort in FY12. The monitor utilizes multivariate analysis and gamma spectroscopy of reprocessing streams to detect small changes in the gamma spectrum, which may indicate changes in process conditions. Multivariate analysis methods common in chemometrics, such as principal component analysis (PCA) and partial least squares regression (PLS), act as pattern recognition techniques, which can detect small deviations from the expected, nominal condition. In past research, a database of training data covering "normal" conditions was used to train these multivariate methods (Orton et al. 2011, 2012). This approach can identify gross changes in process parameters, but small deviations may be obfuscated by the range of training data. As the range of normal conditions included in training increases (e.g., by including fuel samples from many different reactors and operating conditions), the sensitivity of the model to small deviations may decrease. The research efforts in this task extend the MIP Monitor by characterizing the spent fuel samples after initial dissolution. Two main objectives are met by characterizing and classifying the spent fuel at initial dissolution: (1) verifying that the fuel is consistent with written inventories and operation declarations and (2) allowing for fuel-specific multivariate models to monitor conditions later in the process. The initial work in this effort lead to the submission of University of Texas student Kenneth Dayman's master's thesis, Multivariate Analysis Applied to the Characterization of Spent Nuclear Fuel, which describes a multivariate approach to characterizing the reactor type and burn-up of dissolved fuel samples using nuclide activities.

This study used simulated data from ORIGEN-ARP and SYNTH to develop models and algorithms for this fuel characterization, as shown in Figure 2.1. Nuclide activities for prototypic fuel samples were generated using ORIGEN-ARP version 5.1.01 and ENDF/B-VI nuclear data (Bowman and Leal 2000). The development data consisted of three pressurized water reactor (PWR) and three boiling water reactor (BWR) reactor designs, six initial enrichment values evenly distributed among typical commercial values, four cooling times, and nine discharge burn-up values. Spent fuel samples were simulated for each combination of reactor design, burn-up, initial enrichment, and cooling time shown in Table 2.1, resulting in a total of 1296 simulated fuel samples. The 200 nuclides with the highest activity in the ORIGEN- 
ARP output of each fuel sample were then input to SYNTH, a program developed at PNNL to simulate the measured gamma spectra for a specified source. The gamma spectra were simulated for each simulated fuel sample; in each case, the gamma source was treated as a point source $25 \mathrm{~cm}(\sim 10$ inches) from the detector. Air was the only absorber between the source and detector. A coaxial HPGe detector was used, with the detector and counting characteristics given in Table 2.2.

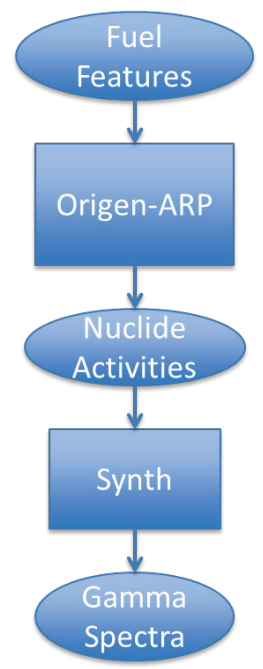

Figure 2.1. Data Simulation Flow

Table 2.1. Spent Fuel Characteristics Used for Data Simulation

\begin{tabular}{|c|c|c|c|c|}
\hline \multirow{2}{*}{$\begin{array}{l}\text { Reactor Design } \\
\text { CE14×14 (PWR) }\end{array}$} & \multicolumn{2}{|c|}{$\begin{array}{c}\text { Burn-up } \\
(\mathbf{M W d} / \mathbf{k g U})\end{array}$} & \multirow{2}{*}{$\begin{array}{c}\begin{array}{c}\text { Initial } \\
\text { Enrichment } \\
(\%)\end{array} \\
2.5\end{array}$} & \multirow{2}{*}{$\begin{array}{c}\begin{array}{c}\text { Cooling } \\
\text { Time } \\
\text { (years) }\end{array} \\
2\end{array}$} \\
\hline & 20 & 40 & & \\
\hline S14×14 (PWR) & 25 & 45 & 3.0 & 3 \\
\hline W17×17 (PWR) & 30 & 50 & 3.5 & 4 \\
\hline Atrium9×9 (BWR) & 34 & & 4.0 & 5 \\
\hline GE7×7 (BWR) & 35 & & 4.5 & \\
\hline SVEA64 (BWR) & 36 & & 5.0 & \\
\hline
\end{tabular}


Table 2.2. HPGe Detector and Electronics Parameters for SYNTH Gamma Spectra Simulations

\begin{tabular}{lll}
\hline \multirow{3}{*}{ End Cap } & Thickness & $0.5 \mathrm{~mm}$ \\
& Material & Aluminum \\
Dead Layer & Spacing & $0.666 \mathrm{~mm}$ \\
& Thickness & $0.666 \mathrm{~mm}$ \\
& Diameter & $6.66 \mathrm{~cm}$ \\
Sensor & Length & $6.66 \mathrm{~cm}$ \\
& Efficiency & $66.60 \%$ \\
& Resolution @1332 keV & $1.666 \mathrm{keV}$ \\
\multirow{2}{*}{ Counting Parameters } & Zero & $0 \mathrm{keV}$ \\
& Gain & $1 \mathrm{keV} / \mathrm{ch}$ \\
ADC & Quad & $0 \mathrm{keV} / \mathrm{ch}^{2}$ \\
Full Scale Energy & Channels & 4096 \\
\hline
\end{tabular}

The simulated gamma spectra were used to develop PLS-based models for classifying and characterizing the dissolved fuel samples; PLS-discriminate analysis (PLSDA) was used to classify the reactor type, and a combination of PLS and locally weighted PLS (LWPLS) models were used to estimate the initial enrichment, burn up, and cooling time. The technical details of these modeling techniques are described in (Coble et al. 2012).

Input selection is a common first step to model development. In general, including inputs that are not useful to the model increases the noise in the model predictions, while withholding important inputs will introduce a prediction bias. The interval-PLS (iPLS) method was used for input selection (Norgaard et al. 2000) [PLS Toolbox help (Eigenvector Research 2011)]. iPLS is a brute force search method that identifies a subset of inputs that give superior predictive performance compared to the full input space. Significant improvement in model prediction accuracy and precision was seen after applying input selection, instead of including the full gamma spectrum. The improved model performance suggests that the multivariate models are targeting key nuclides through specific regions in the spectrum. It may be interesting to identify the nuclides that contribute to the selected peaks for each of the prediction models as was done for the reactor type classifier.

Three algorithms for characterizing dissolved fuel samples were compared: parallel characterization and two sequential algorithms. The characterization errors for each algorithm are shown in Table 2.3. In parallel characterization, each of the four features of interest was estimated using only the gamma spectrum. The two sequential algorithms estimate fuel features using those features that have already been estimated. First classifying the sample's reactor type seemed to be the single best way to improve model predictions. The first sequential algorithm, Algorithm A, classifies the reactor type of the sample and then uses reactor type-specific static PLS models to predict each of the three remaining characteristics. A PLSDA model was trained that perfectly classifies the simulated fuel samples into PWR and BWR fuel types; in all cases, the reactor type can be perfectly classified using this PLSDA model. Algorithm A shows significant improvement over parallel characterization, with improvements of a factor of two to four for prediction of initial enrichment, burn up, and cooling time. A fully sequential characterization algorithm, Algorithm B shown in Figure 2.2, was also evaluated. In this approach, each step in the characterization utilizes the features estimated in previous steps to dynamically train an LWPLS model specific to the estimated features of that fuel sample. Algorithm B shows further 
improvements over Algorithm A for prediction of both initial enrichment and cooling time. The same reactor-specific PLS models are used to predict burn up in both Algorithm A and B, giving a prediction root mean square percent error (RMSPE) on the validation set of approximately $0.1 \%$. The results of the multivariate analyses presented here may be unrealistically accurate, because the data do not contain noise or random perturbations. However, the results suggest that fuel characterization can be effectively performed on dissolved spent fuel samples using gamma spectroscopy.

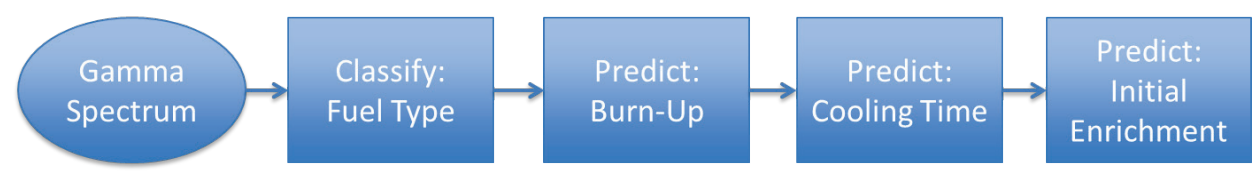

Figure 2.2. Flow Diagram for Automated Fuel Characterization Algorithm (Algorithm B)

Table 2.3. Fuel Characterization RMSPE for Parallel Prediction, Algorithm A, and Algorithm B

\begin{tabular}{lccccccccc}
\hline & \multicolumn{3}{c}{ Parallel Characterization } & \multicolumn{3}{c}{ Algorithm A } & \multicolumn{3}{c}{ Algorithm B } \\
\cline { 2 - 10 } & Overall & PWR & BWR & Overall & PWR & BWR & Overall & PWR & BWR \\
\hline Reactor Type & 0.00 & 0.00 & 0.00 & 0.00 & 0.00 & 0.00 & 0.00 & 0.00 & 0.00 \\
Initial Enrichment & 10.94 & 10.54 & 11.32 & 2.71 & 3.13 & 2.23 & 1.78 & 1.69 & 1.87 \\
Burn Up & 0.36 & 0.42 & 0.29 & 0.11 & 0.09 & 0.13 & 0.11 & 0.09 & 0.13 \\
Cooling Time & 6.62 & 8.65 & 3.81 & 3.39 & 2.96 & 3.79 & 2.13 & 1.26 & 2.80 \\
\hline
\end{tabular}

The models and algorithm developed in this research are based on simulated, noise-free data. While this research suggests that application to real-world data will be successful, the models are not directly applicable to operational data. There are two paths to develop models and an algorithm for deployment. The first path continues to focus on simulated data, but will involve significant work to evaluate and improve the efficacy of these simulations. The fidelity of ORIGEN-ARP simulations should be evaluated for the range of fuel characteristics employed and the 218 nuclides enumerated. This work has already begun, as discussed in the results section; however, the vast majority of the nuclides have not been benchmarked for fuel samples similar to those used here. The gamma spectra resulting from SYNTH also need to be evaluated and benchmarked for fidelity. Additionally, neither simulation accounts for the noise inherent in the system - both process noise and random noise. The ORIGEN-ARP simulation is deterministic; however, there will be variations in the nuclide concentrations due to variations in manufacturing, location in the reactor core and in the fuel pin, differences due to the random nature of radioactive decay, etc. The gamma spectra also suffer from counting noise due to the random nature of radiation. The research presented here did not consider any of these noise terms in simulation or multivariate analysis. The second path to address this concern is to collect and evaluate real-world data, either in lab-scale experiments or from actual operations. Using real-world data will alleviate questions about the fidelity of data and the analysis methods, but it may be difficult to collect a sufficient database of gamma spectra from different fuel samples to develop these models. A proposal to instrument the fuel processing facility at the DOE Savannah River Site (H-Canyon) is currently being pursued to support this data collection; this effort is described in the summary of Task 5. 
Because of the noise sources mentioned above and the uncertainty inherent in multivariate analysis, a deployed fuel characterization should include a measure of uncertainty or confidence; for example, a confidence level of the classification of reactor type or confidence intervals for the initial enrichment, burn up, and cooling time. This will give a more realistic view of the fuel characterization results. These uncertainties will propagate through later monitoring tasks, such as anomaly detection. Understanding the prediction uncertainties and their effects on future analysis is particularly important. Evaluation of the uncertainty associated with multivariate analysis of gamma spectra was initiated this fiscal year. This effort has investigated the impact of gamma-ray counting statistical precision on the effectiveness of principal component regression (PCR), a close relative of PLS. The motivation for this work is to understand how precisely (in the sense of bin-wise counting statistics) gamma-spectra must be measured to make reliable process-control decisions. This understanding in turn will help inform technical requirements for detector size, intrinsic efficiency, dwell time, and energy resolution.

Initial efforts used a simple one-component spectrum with varying "activity" levels, as presented at the March 2012 MPACT Working Group meeting. This was followed by application to a simulated three-component mixture (Am-241, Co-57, and Eu-152) of radioisotopes. In this computational study, the activities of the radioisotopes contributing to an ensemble of synthetic gamma-ray spectra were treated as underlying process variables, to be reconstructed from multivariate analysis of the spectra via PCR. Statistically-independent training and sample-spectrum sets were simulated, with nominal total spectrum counts ranging from 100 to 50,000. The training samples were used to train a PCR model to reconstruct a gamma spectrum; the test spectra were then applied to the model, and the error in spectrum reconstruction was calculated. This analysis was repeated many (1000) times at each nominal total count level to evaluate the effects of Poisson counting statistics. The results, summarized in Figure 2.3, indicate an approximate $1 / \sqrt{\text { counts }}$ dependence of the root mean square (RMS) reconstructed component-activity precision on the total spectrum intensity, when the three spectral components are of comparable intensity. This behavior is consistent with a familiar statistical property of the Poisson distribution, and reflects the Poisson sampling process used to generate random synthetic spectra. The results help to establish one quantitative basis for assessing the minimum number of spectrum counts (which in turn depend upon the detector efficiency, standoff distance, and dwell time per spectrum sample) required for confident PCAbased spectrum analysis and reconstruction of continuous process variables. Similar studies can be performed to determine the minimum requirements for the detector hardware and set up needed to meet a specified precision.

Research to evaluate the effects of counting statistics on prediction uncertainty has utilized simulated spectra to date. However, as mentioned above, limited experimental work is underway to provide data to further develop and confirm the developed framework. A collection of gamma standards mixed in various solutions were measured in prior fiscal years with HPGe detectors; these measurements are being redone with $\mathrm{LaBr}_{3}$ detectors. These two data sets will be applied to the developed uncertainty analysis in early FY13. Additionally, data collected with the experimental flow loop will be available for continuing this analysis. This data collection is described in the summary of Task 6 . 


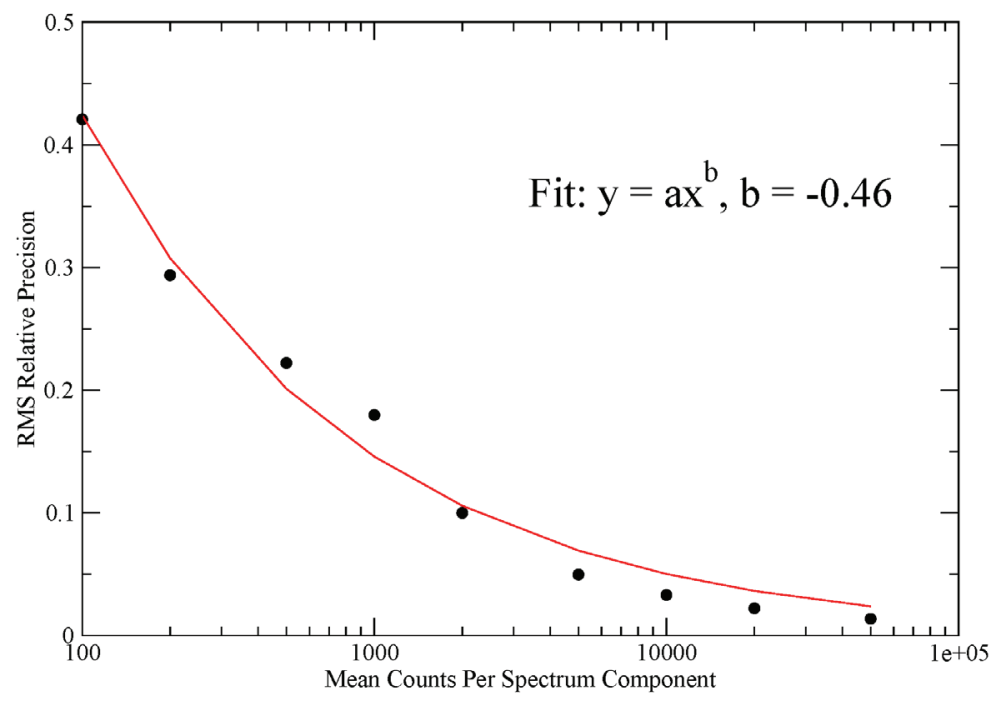

Figure 2.3. Effect of Total Counts on Reconstruction Precision

\subsection{Task 3: Enhanced Gamma-Ray Spectra Collection Techniques}

During FY12, the research conducted on Compton suppression and gamma-gamma coincidence has been performed at Pennsylvania State University and University of Texas at Austin; the PNNL-based effort in this task has been minimal this fiscal year. Sarah Bender (PSU) has lead development of a GEANT model of the PSU Compton suppression system. After the model has been validated with the experimental system, it can be modified to search for a more ideal detector choice and set up for spent fuel solutions measurements. The goal of the research is to develop methods to provide enhanced gamma-ray spectra that contain information that is currently hidden under the large Compton regions from the most intense gamma-rays. Her efforts have been supported mostly by her fellowship, with the project funding a small portion of her and her advisor's interactions with the MIP Monitor project and conference participation.

In support of this work, samples of dissolved spent fuel are being transferred to PSU following an amendment to their license that allows them to receive the samples. This will support their development of the GEANT model by allowing them to compare results of the model to data collected from the spent fuel samples.

\subsection{Task 4: Training of the Next Generation of Nuclear Scientists}

Although Kenneth (Kenny) Dayman (UT-Austin) and Sarah Bender (PSU) are both working on graduate research projects that benefit the MIP Monitor project, their primary support is through their respective fellowships. Kenny completed his Master's degree in May, with a thesis outlining his contributions to the development of a framework for characterizing spent fuel samples. Sarah passed her $\mathrm{PhD}$ qualifying exam in May and plans to complete her degree in 2013. In addition, Nuclear Energy University Program proposals were submitted with both UT-Austin and PSU. 
Kenny visited PNNL for a week in June 2012 to discuss the results of his Master's thesis and begin drafting a journal article summarizing that work. Kenny's $\mathrm{PhD}$ research will not focus on the MIP Monitor; submission of this article is intended to complete his work with this project.

Several journal articles are currently being drafted with Kenny and/or Sarah as the primary author. Kenny and Sarah are jointly preparing an article comparing the multivariate methods for estimating burnup investigated in FY11 to the more conventional gamma-ray methods for burn-up analysis. Kenny is also leading the drafting of a journal manuscript summarizing his Master's thesis as mentioned previously, with the target to submit to the IEEE Transactions on Nuclear Science.

Sarah and Kenny, as well as Professor Sheldon Landsberger (UT-Austin), submitted abstracts to the MARC IX conference that were either directly or peripherally related to the MIP Monitor. Sarah presented her work at the MARC IX conference, and it was later published in the Journal of Radioanalytical and Nuclear Chemistry. Kenny submitted a summary of his MIP Monitor work to the 2012 ANS Winter Meeting, scheduled for November.

\subsection{Task 5: Coordinating the MIP Monitor Project with Related Activities in Other Organizations}

The MIP Monitor continues to coordinate with NA-24 through both the NA-241 Process Monitoring working group and NA-241 Safeguards Technology. A significant effort was made to leverage the H-Canyon measurement exploration activities in NA-241 Safeguards Technology to benefit the MIP Monitor development. A proposal was developed in conjunction with other researchers at PNNL and at Savannah River National Laboratory (SRNL) to install gamma detectors and other fuel monitors at H-Canyon. The proposal was submitted jointly to DOE-NE and NA-24, to leverage the interests of both agencies. This cooperation could provide our project with a large set of empirical gamma spectra with which we can further develop and evaluate the multivariate approach and gain valuable insight into the technical challenges of deployment. The proposal currently remains in planning phases for possible future funding and deployment.

Collaboration with the Chinese is still possible, but little has changed on that front. Preparations for this interaction have been made, although their planned tour of PNNL has yet to occur.

Finally, an abstract regarding an overview of the MIP Monitor technology was previously submitted to the GLOBAL 2011 conference in Japan. The abstract was accepted, and invited for a presentation. The MIP Monitor was presented at the conference in December by PNNL staff member David Wootan, whose attendance to the foreign conference was funded internally by PNNL. Our project was well received, and there is potential for collaboration with the Japanese, although the steps forward are unclear at this point.

\subsection{Task 6: Bench-Scale Flow Loop Experimentation and Analysis}

A bench-scale flow loop was designed and constructed in FY11 for dynamic data collection to test the near-real-time analysis of the MIP Monitor. Spectra from dilute dissolved spent nuclear fuel samples were collected using a $\mathrm{LaBr}_{3}$ detector. The flow loop design allows for the mixing of gamma signals

without actually mixing the spent fuel solutions by filling various tubes with a single fuel type. In FY11, 
an experiment was run to collect "fuel mixing" data. Initially, static spectra for the system containing only one fuel type were collected as calibration data. In this case, 300 s spectra were collected for both one and two full tubes of a single fuel type for each of the three fuels; these spectra were collected in triplicate. Additionally, two 300s spectra were collected for each mixture of fuel types wherein two tubes were full of a different fuel each, resulting in duplicate spectra for ATM 105a and ATM 105p, ATM 105a and ATM 109, and ATM 105p and ATM 109. Dynamic spectra were collected using the bench-top flow loop under the following conditions: first a 300s spectrum was collected with a single channel tube full of one fuel type. Then, a series of 30 s counts was initiated to begin with the filling of a second channel tube with a different dissolved fuel. A total of six to fourteen 30 s spectra were collected for each run. Once the second channel tube was completely filled, a 300s spectrum was recorded. Early FY12 efforts focused on analyzing this data. The results of this data analysis were presented at the March MPACT Working Group meeting and at ATALANTE 2012 (Schwantes et al. 2012); the results are summarized here.

To perform dynamic spectra classification, a PCA model was developed for fuel classification with six possible fuel classifications: 105a, 105p, 109, 105a+105p, 105a+109, and 105p+109. The three single-fuel classes are built on spectra collected from a single full tube of fuel; the three two-fuel classes are built on spectra collected from two-tube samples, with one full tube of each component fuel type. As new spectra are collected, they are transformed to the PC-space and compared to the existing classification map. Figure 2.4 shows one example of this type of classification, for a system moving from ATM 105p fuel to ATM 109 fuel indicated by connected black dots. Additional runs were evaluated for moving between all combinations of two fuel types, with similar results showing that fuel classification is possible using a PCA-based classification approach.

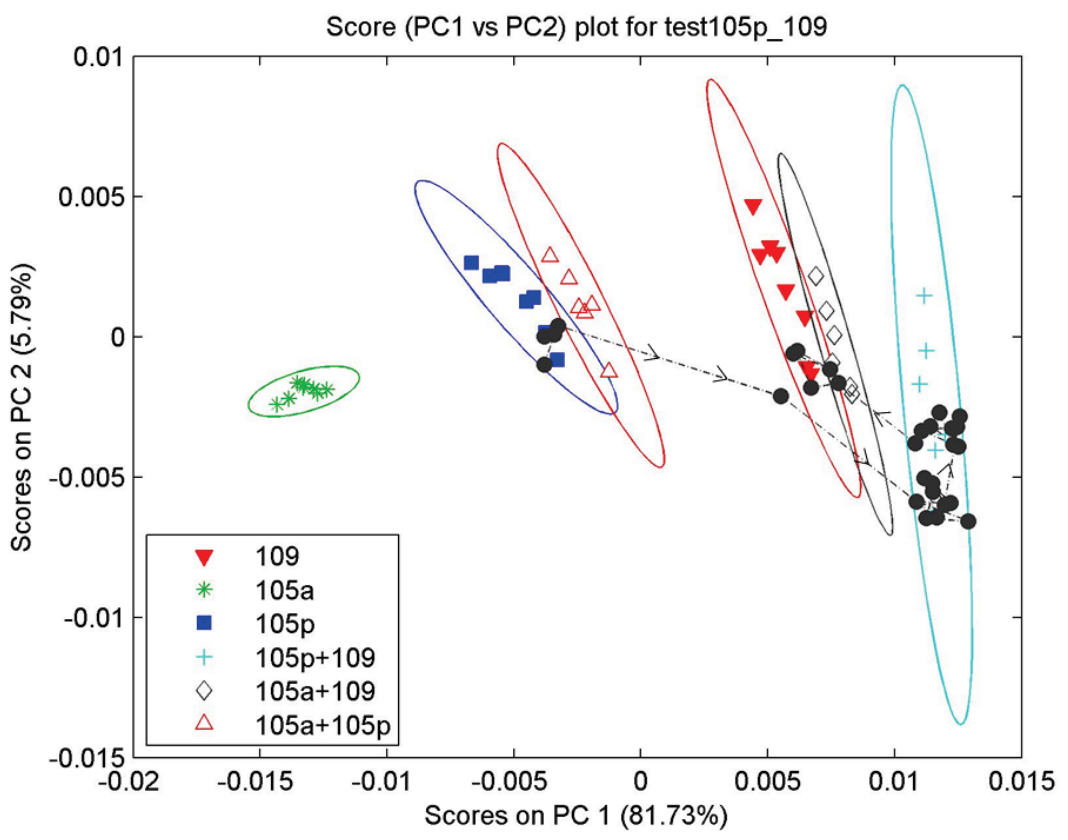

Figure 2.4. Dynamic Fuel Classification Results 
While the use of the bench-scale test loop proved adequate for dynamically testing the MIP Monitor, this experimental design did lead to a few drawbacks for multivariate analysis. Specifically, two problems inhibit the classification analysis: (1) a mismatch in counting time and (2) a mismatch in the amount of fuel being counted at any time. The first problem is straightforward to address, because all collected spectra are normalized by the total number of counts in the spectra, resulting in normalized spectra with a total area of one. This maintains the overall shape of the spectra while eliminating the differing effects of amplitude introduced by the different counting times. Unfortunately, the second problem cannot be addressed with simple data processing. There is no easy way to artificially transform a spectrum collected from a sample of mass $m$ to simulate one expected from a sample of mass $2 m$.

The bench-scale flow loop was again modified in Q4 of FY12 to provide more consistent control of the volume of material in front of the detector at any given time. The updated system is shown in Figure 2.5. In addition to updating the pump and flow path to provide additional control, the detector data was collected in "event mode," meaning that each detected gamma was recorded, instead of recording 30s (or 300s) spectra. This will support the MIP Monitor development in several ways. First, the use of event mode counting will allow for spectra of multiple counting times to be extracted in post-analysis. These spectra can be used to test and confirm the uncertainty analysis framework described in Task 2 . Additionally, the proposed H-Canyon deployment includes the use of event mode counting; this smallscale use will provide valuable experience to determine if the advantages of event mode counting (primarily, greater flexibility in data analysis) will outweigh the drawbacks (significantly larger data storage requirements). The flow loop experiment was redone using this set up in late FY12. Analysis of this data, both for dynamic fuel classification and uncertainty analysis, is planned for early FY13.

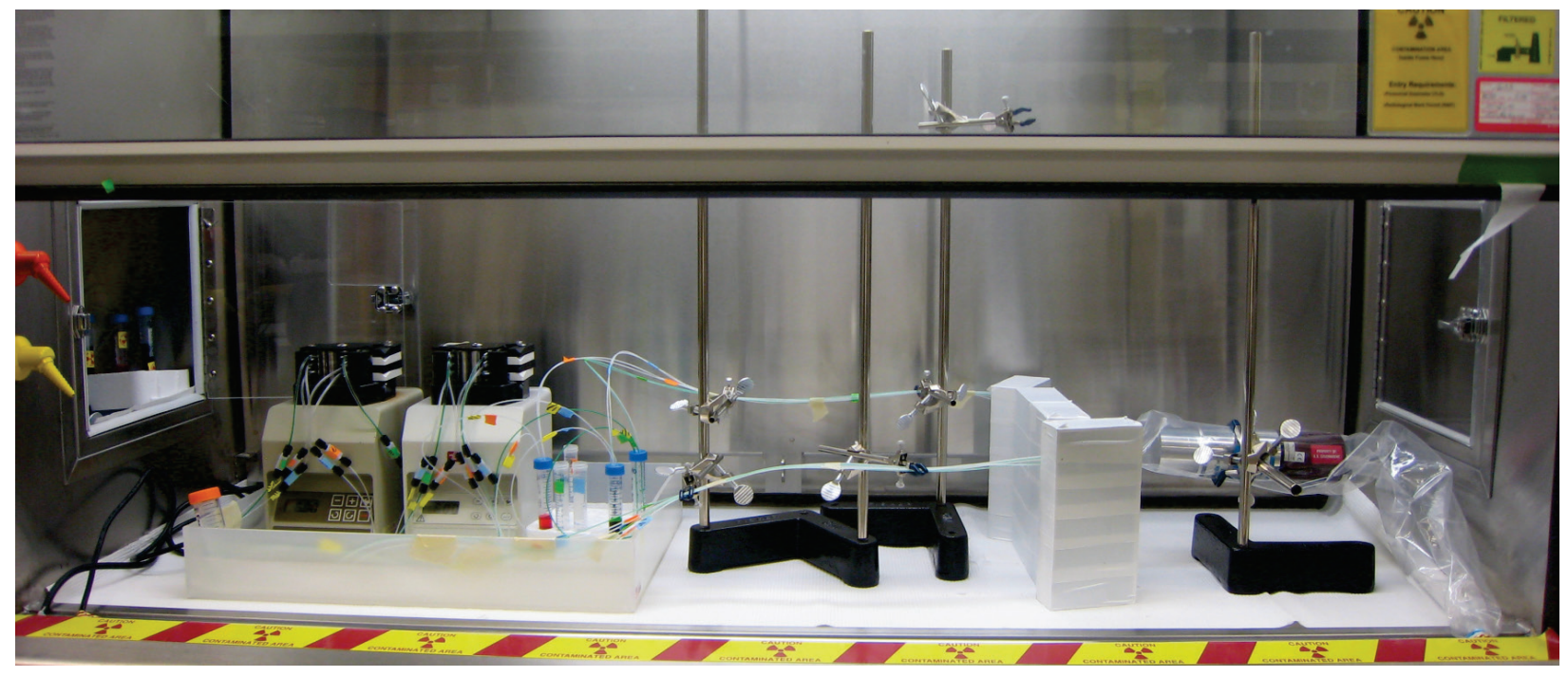

Figure 2.5. Photograph of the Updated Bench-Scale Flow Loop System 



\subsection{Conclusion}

The MIP Monitor project had several accomplishments during FY12, including:

- An automated algorithm for characterizing dissolved spent fuel samples according to reactor type, initial enrichment, burn up, and cooling time was developed and documented. Milestone report submitted in July 2012.

- A framework for characterizing the propagation of uncertainty in multivariate analysis of gamma spectra was developed. Experimental work to provide data to further develop and confirm the approach was performed; analysis of this data is planned for FY13.

- Spent fuel solutions were maintained to provide continued access to spent fuel solutions for testing of the MIP Monitor. Samples are being transferred to PSU to support their work related to the MIP Monitor.

- Data from the bench-scale flow loop designed and constructed in FY11 were analyzed. Results led to modifications of the flow loop to provide better process control and utilize event mode counting. Data collected on the modified loop will be analyzed in early FY13.

- One graduate student, Kenny Dayman at UT-Austin, published a master's thesis on work directly related to the MIP Monitor project.

- Efforts continue on several fronts to engage international partners with the intent to collaborate in order to gain access to large amounts of reprocessing data for further MIP Monitor development.

- A proposal was developed and submitted to DOE-NE and NA-24 to instrument the H-Canyon reprocessing facility at SRNL with gamma detectors in order to collect data to further develop and demonstrate the MIP Monitor.

- The MIP Monitor research and development was presented and published in several forums, including several related to the MIP Monitor that were funded either internal to the lab or whose funding was shared between DOE programs. 



\subsection{Future Work}

Research efforts in FY13 will focus on evaluating the applicability and efficacy of the MIP Monitor to pyroprocessing reprocessing systems. Work will also continue to develop the uncertainty analysis framework to help determine the technical requirements for detector size, intrinsic efficiency, dwell time, and energy resolution for deployment of gamma detectors for the MIP Monitor. Experimental work, including using the bench-scale flow loop, will continue as required by method development.

Pennsylvania State University, with oversight from PNNL, will continue to develop their GEANT model and compare model results to experimental results from provided spent fuel samples. The PNNL team will continue to support the training of students and young staff. Efforts will continue to be made to secure domestic and international partners to gain access to spectral process data that can aid in the development of the MIP Monitor techniques. Significant results from all aspects from the MIP Monitor research will continue to be published in peer-reviewed journals and presented at conferences. 



\subsection{References}

Benedict M, TM Pigford and HW Levi. 1981. Nuclear Chemical Engineering. McGraw-Hill, New York.

Bowman SM and LC Leal. 2000. ORIGEN-ARP: Automatic Rapid Process for Spent Fuel Depletion, Decay, and Source Term Analysis. NUREG/CR-0200, U.S. Nuclear Regulatory Commission, Washington, D.C.

Coble JB, CR Orton and JM Schwantes. 2012. Automated Characterization of Spent Fuel through the Multi-Isotope Process (MIP) Monitor. PNNL-21599, Pacific Northwest National Laboratory.

DOE. 2010. "Nuclear Energy Research and Development Roadmap." U.S. Department of Energy (DOE), Washington, DC. http://nuclear.gov/pdfFiles/NuclearEnergy_Roadmap_Final.pdf.

Eigenvector Research. 2011. Interval PLS (iPLS) for Variable Selection. Accessed July 24, 2012 Available at http://wiki.eigenvector.com/index.php?title=Interval_PLS_(IPLS)_for_Variable_Selection.

Norgaard L, A Saudland, J Wagner, JP Nielsen, L Munck and SB Engelsen. 2000. "Interval Partial Least-Squares Regression (iPLS): A Comparative Chemometric Study with an Example from NearInfrared Spectroscopy." Applied Spectroscopy 54(3):413-419.

Orton CR, CG Fraga, RN Christensen and JM Schwantes. 2011. "Proof of Concept Simulations of the Multi-Isotope Process Monitor: An Online, Nondestructive, Near-Real-Time Safeguards Monitor for Nuclear Fuel Reprocessing Facilities." Nuclear Instruments and Methods in Physics Research Section A: Accelerators, Spectrometers, Detectors and Associated Equipment 629(1):209-219.

Orton CR, CG Fraga, RN Christensen and JM Schwantes. 2012. "Proof of Concept Experiments of the Multi-Isotope Process Monitor: An Online, Nondestructive, Near Real-Time Monitor for Spent Nuclear Fuel Reprocessing Facilities." Nuclear Instruments and Methods in Physics Research Section A: Accelerators, Spectrometers, Detectors and Associated Equipment 672:38-45.

Orton CR, CG Fraga, M Douglas, RN Christensen and JM Schwantes. 2009a. "Monitoring Spent Nuclear Fuel Reprocessing Conditions Non-Destructively and in Near-Real-Time Using The MultiIsotope Process (MIP) Monitor." In 2nd JAPAN-IAEA Workshop on Advanced Safeguards Technology for the Future Nuclear Fuel Cycle, Tokai-mura, Japan. International Atomic Energy Agency, Vienna, Austria.

Orton CR, JM Schwantes, S Bryan, T Levitskaia, D Duckworth, M Douglas, OT Farmer, CG Fraga, S Lehn, M Liezers, S Peper and RN Christensen. 2008. "Advanced Safeguards Technology Demonstration at Pacific Northwest National Laboratory." In 49th INMM Annual Meeting. July 13-17, 2008, Nashville, Tennessee. Institute of Nuclear Materials Management (INMM), Deerfield, Illinois.

Orton CR, JM Schwantes, CG Fraga, M Douglas and RN Christensen. 2009b. "Experimental Validation of the Multi-Isotope Process Monitor Concept." In GLOBAL 2009, Paris, France. American Nuclear Society, La Grange Park, Illinois.

OTA. 1995. Nuclear Safeguards and the International Atomic Energy Agency. Report No. OTA-ISS615, Office of Technology Assessment (OTA), Washington, D.C. 
Schwantes JM, SA Bryan, DC Duckworth, TG Levitskaia, SH Pratt, JB Coble, M Liezers, GL Hart and CR Orton. 2012. "Advanced Process Monitoring Safeguards Technologies at Pacific Northwest National Laboratory." In ATALANTE 2012 International Conference. August 30, 2012, Montpellier, France.

Schwantes JM, M Douglas, CR Orton, CG Fraga and RN Christensen. 2008. "Multi-Isotope Process (MIP) Monitor: a Near-Real-Time Monitor for Reprocessing Facilities." In Transactions from the Annual Meeting, Anaheim, California. American Nuclear Society, La Grange Park, Illinois.

Schwantes JM, CR Orton, CG Fraga, M Douglas and RN Christensen. 2009. "The Multi-Isotope Process (MIP) Monitor: A Near-Real-Time, Nondestructive, Indicator of Spent Nuclear Fuel Reprocessing Conditions." In 50th INMM Annual Meeting. July 12-16, 2009, Tucson, Arizona.

Smith LE, JM Schwantes, JJ Ressler, M Douglas, KA Anderson, CG Fraga, PC Durst, CR Orton and RN Christensen. 2007. "Next Generation On-line MC\&A Technologies for Reprocessing Plants." In GLOBAL 2007 Conference on Future Nuclear Energy System. September 9-13, 2007, Boise, Idaho. American Nuclear Society, La Grange Park, Illinois. 



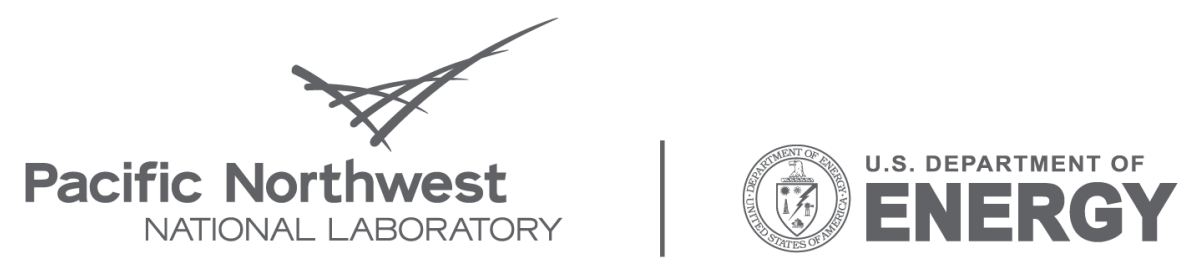

Proudly Operated by Battelle Since 1965

902 Battelle Boulevard

P.O. Box 999

Richland, WA 99352

1-888-375-PNNL (7665)

www.pnl.gov 